\title{
A gestão da informação sob a ótica do pensamento complexo: uma reflexão
}

\author{
Beatriz Rosa Pinheiro dos Santos \\ Universidade Estadual Paulista, Faculdade de Filosofia e Ciências, \\ Departamento de Ciência da Informação, Marília, SP, Brasil \\ pinheiro.santos@unesp.br \\ Marta Lígia Pomim Valentim \\ Universidade Estadual Paulista, Faculdade de Filosofia e Ciências, \\ Departamento de Ciência da Informação, Marília, SP, Brasil \\ valentim@valentim.pro.br \\ leda Pelógia Martins Damian \\ Universidade Estadual Paulista, Faculdade de Filosofia e Ciências, \\ Departamento de Ciência da Informação, Marília, SP, Brasil \\ iedapm@usp.br
}

DOI: https://doi.org/10.26512/rici.v13.n1.2020.23413

Recebido/Recibido/Received: 2019-03-06

Aceitado/Aceptado/Accepted: 2019-10-01

Resumo: A sociedade contemporânea imersa em uma quantidade significativa de informação deve integrar os mais variados contextos organizacionais e informacionais, a fim de gerar conhecimento com características inter, multi, pluri e transdisciplinares. Nesse cenário, a informação e o conhecimento produzidos necessitam da intervenção do pensamento complexo para a própria valorização e desenvolvimento eficaz de seus processos. No intuito de contribuir para agregar valor aos processos informacionais, apresenta-se o seguinte problema: é possível agregar valor às práticas tradicionais da gestão da informação, por meio dos princípios do pensamento complexo? Objetiva-se discorrer sobre a gestão da informação em consonância à ótica do pensamento complexo. A justificativa para o desenvolvimento de tal pesquisa reside em contribuir para o arcabouço teórico da Ciência da Informação que, por sua vez, estuda a gestão da informação nos mais variados contextos organizacionais. Para tanto, realizou-se uma revisão de literatura, em que foi possível verificar quais aspectos do pensamento complexo podem auxiliar na quebra de paradigmas que habitam as práticas tradicionais oriundas de distintos modelos de gestão da informação.

Palavras-Chave:Gestão da Informação. Teoria da Complexidade. Pensamento Complexo.

\section{The management of information under the optics of complex thought: a reflection}

Abstract: The contemporary society immersed in a significant amount of information must integrate the most varied organizational and informational contexts in order to generate knowledge with inter, multi, multi and transdisciplinary characteristics. In this scenario, the information and knowledge produced requires the intervention of complex thinking for the proper valuation and effective development of its processes. In order to contribute to add value to informational processes, the following problem arises: Is it possible to add value to traditional information management practices, through the principles of complex thinking? The aim is to discuss the information management in line with the view of complex 
thinking. The justification for the development of such research lies in contributing to the theoretical framework of Information Science which, in turn, studies information management in the most varied organizational contexts. Therefore, a literature review was carried out, in which it was possible to verify which aspects of the complex thinking can help in the breaking of paradigms that inhabit the traditional practices coming from different models of information management.

Keywords: Information Management. Theory of Complexity. Complex Thinking.

La gestión de la información bajo la óptica del pensamiento complejo: una reflexión

Resumen: La sociedad contemporánea inmersa en una cantidad significativa de información debe integrar los más variados contextos organizacionales e informacionales, a fin de generar conocimiento con características inter, multi, pluri y transdisciplinares. En este escenario, la información y el conocimiento producidos necesitan la intervención del pensamiento complejo para la propia valorización y desarrollo eficaz de sus procesos. Con el fin de contribuir a agregar valor a los procesos informacionales, se presenta el siguiente problema: ¿es posible agregar valor a las prácticas tradicionales de la gestión de la información, a través de los principios del pensamiento complejo? Se pretende discurrir sobre la gestión de la información en consonancia con la óptica del pensamiento complejo. La justificación para el desarrollo de tal investigación reside en contribuir al marco teórico de la Ciencia de la Información que a su vez estudia la gestión de la información en los más variados contextos organizacionales. Para ello, se realizó una revisión de literatura, en la que fue posible verificar qué aspectos del pensamiento complejo pueden auxiliar en la ruptura de paradigmas que habitan las prácticas tradicionales oriundas de distintos modelos de gestión de la información.

Palabras clave: Gestión de la Información. Teoría de la complejidad. Pensamiento Complejo.

\section{Introdução}

As pessoas, em seus mais variados ambientes de atuação, executam diariamente atividades que, muitas vezes, fazem parte de processos fragmentados. Além disso, os fatos vivenciados devem ter uma razão e uma explicação que justifiquem sua ocorrência, cujas problemáticas necessitam de conhecimentos ampliados, entretanto, o que se observa é o uso/aplicação de conhecimento oriundo de um único campo de conhecimento, cujos métodos não se misturam com outras áreas do saber, ou seja, a superespecialização e a separabilidade são princípios ainda praticados, mesmo em uma época que se autodenomina de pós-moderna. Morin (2000, p. 41) explica que “[...] estamos num período entre dois mundos, um, que está prestes a morrer, mas que não morreu ainda, e outro, que quer nascer, mas que não nasceu ainda".

A gestão da informação, subárea de estudo do campo da Ciência da Informação, sendo esta última considerada por Wersig (1993) como um protótipo de um novo tipo de Ciência, possui característica pós-moderna que deve ser enfatizada na conjuntura atual.

A sociedade contemporânea imersa em uma quantidade significativa de informação deve integrar os mais variados contextos organizacionais e informacionais, a fim de gerar conhecimento com características inter, multi, pluri e transdisciplinares que, em parte, são responsáveis pela formação da Sociedade Pós-Moderna. De acordo com Pombo (2005), a interdisciplinaridade ressalta a ideia de relação recíproca entre distintas áreas do 
conhecimento; a multi e a pluridisciplinaridade evidencia uma competência que, ao mesmo tempo, reúne e individualiza campos distintos de conhecimento e, por fim, a transdisciplinaridade é compreendida por esta autora como sendo a união de disciplinas e ideias que ultrapassam o estabelecido por elas, ou seja, se refere ao potencial para a criação de novos conceitos.

Nessa perspectiva, infere-se que a informação e o conhecimento produzidos necessitam da intervenção do pensamento complexo, para que haja a valorização e o desenvolvimento eficaz dos processos inerentes.

Para Morin (2000), o pensamento científico clássico é baseado em três pilares: a "ordem", a "separabilidade" e a "razão". Nesse sentido, para este autor, o pensamento complexo surge para integrar os princípios da Ciência Clássica a uma visão mais rica e contestadora. "O pensamento complexo não substitui a separabilidade pela inseparabilidade ele convoca uma dialógica que utiliza o separável, mas o insere na inseparabilidade" (MORIN, 2000 , p. 201), ou seja, o pensamento descrito pode elevar o poder de discussão e interação entre diferentes áreas do conhecimento, bem como ao fluxo de informação e conhecimento presentes nessas áreas.

Devido a grande massa informacional produzida pela sociedade, a gestão da informação passa a ser um processo imprescindível para seu efetivo gerenciamento. A gestão pode ser considerada um conjunto de etapas relativas à identificação das necessidades de informação, aquisição, organização, armazenamento, disseminação, uso e desenvolvimento de produtos e serviços de informação (CHOO, 2003).

A Teoria da Complexidade é denominada por Morin (2007) como um conjunto de novas reflexões e descobertas, que objetivam reunir, distinguir, mas não separar as áreas de conhecimento e os contextos e ideias nelas presentes. O pensamento complexo se configura como uma quebra de paradigma que visa desconstruir termos, processos, pensamentos e ferramentas existentes e, ao mesmo tempo, construí-los com novas características que privilegiem a integração, a união e a força do todo. Nesse âmbito, a Teoria da Complexidade pode auxiliar na integração e reunião das etapas inerentes à gestão da informação.

Com base nessas explanações, apresenta-se o seguinte problema de pesquisa: é possível agregar valor às práticas tradicionais da gestão da informação por meio dos princípios do pensamento complexo?

Objetiva-se discorrer sobre a gestão da informação em consonância à ótica do pensamento complexo. Acredita-se que esta pesquisa pode contribuir para o avanço do arcabouço teórico da Ciência da Informação que, por sua vez,contempla os estudos voltados à gestão da informação nos mais variados contextos organizacionais. 


\section{Gestão da informação}

A gestão da informação é investigada por distintas abordagens e diferentes campos do conhecimento, como exemplo pode-se citar: a Ciência da Computação que investiga a gestão de dados, os sistemas que os congregam e as variáveis que influem nesses processos; a Administração que estuda os fenômenos afetos a gestão de sistemas de informação e das pessoas enquanto sujeitos organizacionais, visando avaliar seus comportamentos e desempenhos frente a informação e o conhecimento; a Ciência da Informação que investiga os fenômenos informacionais no âmbito da gestão da informação, abrangendo a cultura, as pessoas e as tecnologias de informação e conhecimento (WILSON, 2002).

Nesse contexto, abrangente acerca da gestão da informação que a Ciência da Informação envolve, Madsen (2013) ressalta que a gestão da informação possui abordagens interdisciplinares necessárias para o alcance de resultados efetivos nos contextos abarcados por suas atividades e etapas.

Barbosa (2008) explica que a gestão da informação, em seu contexto histórico, ganhou destaque para ser estudada devido à grande explosão informacional, assim como com o advento das tecnologias de informação e comunicação, evidenciando a informação como um recurso imprescindível a ser gerenciado. Nesse sentido, a gestão da informação passa a ser uma ferramenta estratégica e necessária do ponto de vista econômico, que surge para mediar os processos informacionais na denominada Sociedade da Informação (MALIN, 2012).

A gestão da informação possui inúmeros conceitos, desenvolvidos por diversos autores. De acordo com McGee e Prusak (1994) é desenvolvida por meio de processos se constituindo em um conjunto de tarefas que devem estar conectadas entre si e entre o ambiente em que está inserido. Nessa perspectiva, Choo (2003) corrobora que a gestão da informação é considerada uma rede de processos que objetiva adquirir, criar, organizar, distribuir e usar a informação.

De acordo com Valentim (2004), a gestão da informação é realizada em ambientes organizacionais em há produção de informação registrada que, por sua vez, perpassam os fluxos formais existentes em uma determinada organização. De uma maneira abrangente, esta conceitua a gestão da informação como um conjunto de atividades que identificam as necessidades informacionais, mapeiam, coletam, filtram, analisam, organizam, armazenam e disseminam a informação, no intuito de apoiar o processo decisório em ambientes organizacionais. 
Silva e Tomaél (2007) acreditam que mais do que gerenciar informação registrada, a gestão da informação compreende os processos que analisam as pessoas envolvidas com a produção e utilização da informação, bem como os recursos aplicados para tal ação como, por exemplo, as tecnologias de informação, fontes, serviços e sistemas informacionais. Desse modo, a gestão da informação torna-se responsável por gerir não somente os recursos internos, mas também os externos.

Nessa mesma linha de raciocínio, Ponjuán Dante (2007, p. 91, tradução nossa) explica que "As pessoas não são apenas as que projetam, mas são também as que manuseiam e utilizam os sistemas de informação". Para esta autora, algumas operações relacionadas aos sistemas de informação podem ser efetuadas por máquinas, contudo, somente as pessoas podem dar a verdadeira qualidade e diferenciais aos processos, visto que as pessoas "[...] têm a capacidade de criar e transformar o mundo" (PONJUÁN DANTE, 2004, p. 91, tradução nossa).

Logo, para a autora supracitada, a gestão da informação se configura em processos que utilizam os recursos econômicos, físicos, humanos e materiais para o gerenciamento e uso da informação nos mais diversos contextos organizacionais e da sociedade.

Do ponto de vista de McGee e Prusak (1994), a gestão da informação abrange as etapas básicas de identificação, coleta, tratamento, classificação, disseminação e uso da informação. Para estes autores, essas etapas são exclusivamente desenvolvidas com um cunho estratégico para a tomada de decisão em contextos empresariais.

Davenport e Prusak (2002), também,contribuem para a construção dos diversos conceitos pertencentes à gestão da informação, enfocando os fundamentos da ecologia da informação, que se constituem em gerenciar a informação, bem como os aspectos comportamentais do ser humano e da sua relação com o mundo informacional.

A fim de proporcionar uma melhor compreensão sobre esses conceitos, foram selecionados alguns modelos de gestão da informação de pesquisadores desta temática: Modelo de McGee e Prusak (1994), Modelo de Davenport (1994), Modelo de Choo (2003), e Modelo de Valentim (2004).

\subsection{Modelos de Gestão da Informação}

O modelo de gestão da informação de McGee e Prusak (1994) apresenta processos separados, que quando executados se transformam em gerenciamento de informações. Os processos são denominados como: Identificação de necessidades de informação; Coleta/entrada de informação; Classificação e armazenamento de informação; Tratamento e apresentação da informação; Desenvolvimento de produtos e serviços de informação; Distribuição e disseminação da informação; e Análise e uso da informação. 


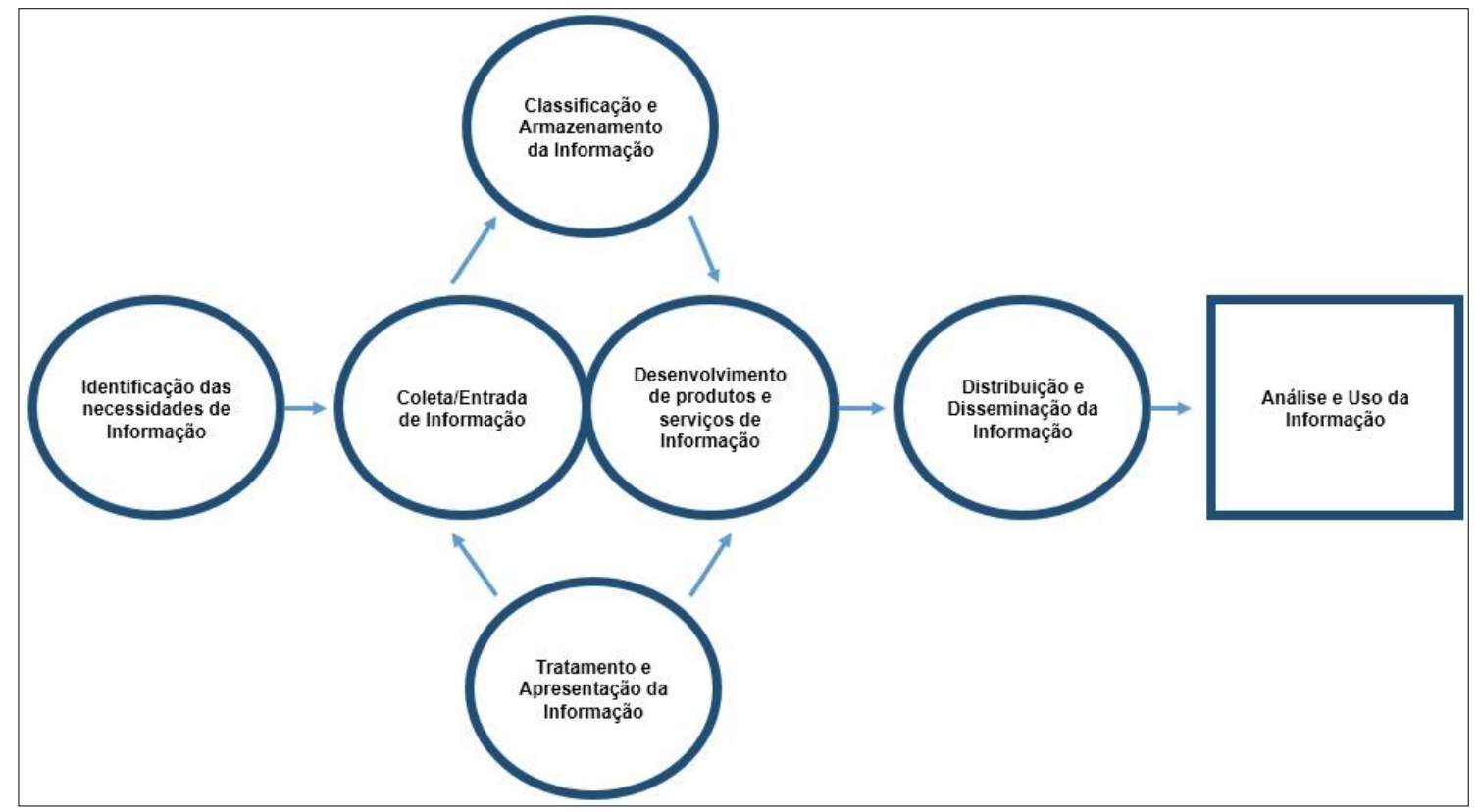

Figura 1: Modelo Processual de Gestão da Informação de McGee e Prusak

Fonte: McGee e Prusak (1994, p. 108).

O modelo de Davenport (1994) possui características que agregam valor à subjetividade do ser humano, cujos processos abrangem: Determinação das exigências de

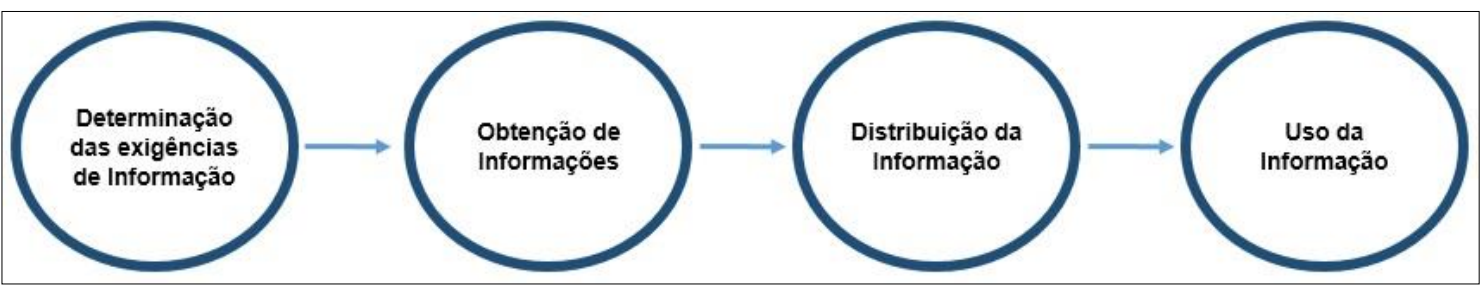

informação; Obtenção de informações; Distribuição da informação; e Uso da informação.

Figura 2: Modelo Processual de Gestão da Informação de Davenport

Fonte: Davenport (2002, p. 175).

O modelo de gestão da informação de Choo (2003) segue uma linha de raciocínio voltada à organização do conhecimento e a valorização do conhecimento tácito dos funcionários que, por sua vez, adquirem conhecimento por meio da informação. Os processos deste modelo se dividem em: Identificação das necessidades informacionais; Aquisição da informação; Organização e armazenamento da informação; Desenvolvimento de produtos e serviços de informação; Distribuição da informação; e Uso da informação. 
Figura 3: Modelo Processual de Gestão da Informação de Choo

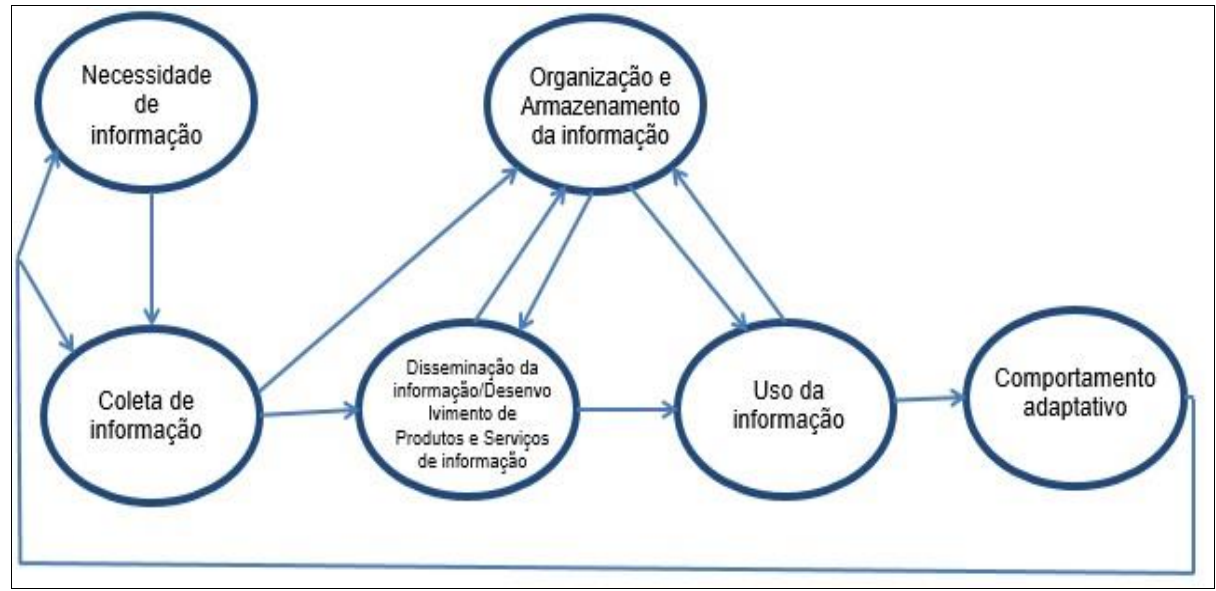

Fonte: Choo (2002, p. 24).

Por fim, Valentim (2004) desenvolve um modelo denominado de "atividades base da gestão da informação" composto por: Identificar demandas e necessidade de informação; Mapear e reconhecer fluxos formais; Desenvolver a cultura organizacional positiva em relação ao compartilhamento e socialização da informação; Proporcionar a comunicação informacional de forma eficiente, utilizando tecnologias de informação e comunicação; Prospectar e monitorar informações; Coletar, selecionar e filtrar informações; Tratar, analisar, organizar, armazenar informações, utilizando tecnologias de informação e comunicação; Desenvolver sistemas corporativos de diferentes naturezas, visando o compartilhamento e uso da informação; Elaborar produtos e serviços informacionais; e Fixar normas e padrões de sistematização da informação.

Quadro 1 - Modelo de Gestão da Informação de Valentim 


\begin{tabular}{|c|}
\hline $\begin{array}{c}\text { Gestão da Informação } \\
\text { Âmbito } \\
\text { Fluxos Formais }\end{array}$ \\
\hline $\begin{array}{l}\text { Objeto } \\
\text { Conhecimento Explícito }\end{array}$ \\
\hline Atividades Base \\
\hline$\checkmark \quad$ Identificar demandas e necessidades de informação. \\
\hline$\checkmark \quad$ Mapear e reconhecer fluxos formais. \\
\hline $\begin{array}{llllll}\checkmark & \text { Desenvolver a cultura organizacional positiva } & \text { em } & \text { relação } & \text { ao } \\
\text { compartilhamento/socialização de informação. }\end{array}$ \\
\hline $\begin{array}{l}\checkmark \text { Proporcionar a comunicação informacional de forma eficiente, utilizando tecnologias } \\
\text { de informação e comunicação. }\end{array}$ \\
\hline$\checkmark$ Prospectar e monitorar informações. \\
\hline$\checkmark$ Coletar, selecionar e filtrar informações. \\
\hline $\begin{array}{l}\checkmark \text { Tratar, analisar, organizar, armazenar informações, utilizando tecnologias de } \\
\text { informação e comunicação. }\end{array}$ \\
\hline $\begin{array}{l}\checkmark \text { Desenvolver sistemas corporativos de diferentes naturezas, visando o } \\
\text { compartilhamento e uso da informação. }\end{array}$ \\
\hline$\checkmark \quad$ Elaborar produtos e serviços informacionais. \\
\hline Fixar normas e padrões de sistematização da informação. \\
\hline$\checkmark$ Retroalimentar o ciclo. \\
\hline
\end{tabular}

Fonte: Valentim (2004).

Por fim, Valentim (2004) desenvolve um modelo denominado de "atividades base da gestão da informação" composto por: Identificar demandas e necessidade de informação; Mapear e reconhecer fluxos formais; Desenvolver a cultura organizacional positiva em relação ao compartilhamento e socialização da informação; Proporcionar a comunicação informacional de forma eficiente, utilizando tecnologias de informação e comunicação; Prospectar e monitorar Os modelos de gestão da informação serão utilizados para as reflexões e discussões apresentadas na próxima seção deste texto.

Todos esses modelos apresentam uma perspectiva de atividades de gestão da informação que são voltadas aos processos gerenciais de um ambiente organizacional, baseados em um mesmo contexto que se direciona pelas seguintes etapas: identificação de necessidades informacionais, coleta, organização, coleção, armazenamento, disseminação e uso da informação. Todavia, a fim de analisar com mais propriedade o contexto da complexidade da informação inserida na gestão da informação, buscou-se apresentar outros tipos de modelos que se diferenciam do padrão descrito anteriormente. Os modelos são de Paéz Urdaneta (1992), Butcher y Rowley (1998) e de Ponjuán Dante (2000).

\section{Quadro 2 - Modelo de Gestão da Informação de Páez Urdaneta}




\begin{tabular}{|c|c|}
\hline \multicolumn{2}{|r|}{ Gestão de Recursos de Informação } \\
\hline$\checkmark$ & Mapeamento da distribuição dos recursos de informação. \\
\hline$\checkmark$ & Monitoramento do uso de recursos de informação. \\
\hline$\checkmark$ & Custo e valor dos recursos de informação. \\
\hline$\checkmark$ & Desenvolvimento dos perfis de informação necessários. \\
\hline$\checkmark$ & Coordenação da aquisição dos recursos de informação. \\
\hline$\checkmark$ & Estabelecimento da contabilidade da gestão da informação. \\
\hline$\checkmark$ & Monitoramento do gerenciamento teórico dos recursos de informação. \\
\hline$\checkmark$ & Proteção da Inteligência Organizacional. \\
\hline \multicolumn{2}{|r|}{ Gestão da Informação Estratégica } \\
\hline$\checkmark$ & Relacionar o planejamento corporativo com o planejamento estratégico. \\
\hline$\checkmark$ & Avaliar a base informativa e as necessidades das atividades de apoio e de linha. \\
\hline$\checkmark$ & Melhorar a qualidade da conexão de informação entre as atividades de linha. \\
\hline$\checkmark$ & Obter inteligência externa para apoiar as atividades da linha. \\
\hline$\checkmark$ & $\begin{array}{l}\text { Monitoramento do impacto da gestão estratégica nas atividades competitivas da } \\
\text { organização. }\end{array}$ \\
\hline \multicolumn{2}{|r|}{ Gestão Holística da Informação } \\
\hline$\checkmark$ & Otimizar a natureza da informação nas diferentes funções gerenciais. \\
\hline$\checkmark$ & Otimizar os processos de tomada de decisão nos níveis médio e superior. \\
\hline$\checkmark$ & Melhorar a qualidade do trabalho individual mediante a agregação de valor. \\
\hline$\checkmark$ & Promover o uso efetivo da base informacional da organização. \\
\hline$\checkmark$ & $\begin{array}{l}\text { Monitorar tendências externas que podem influenciar no ambiente informativo da } \\
\text { organização e no setor local de informação. }\end{array}$ \\
\hline$\checkmark$ & Avaliar o impacto da gestão da informação no ambiente social e laboral da organização. \\
\hline$\checkmark$ & Promover a filosofia da gestão entre os membros da organização. \\
\hline
\end{tabular}

Fonte: Adaptado de Páez Urdaneta (2004).

O modelo de gestão da informação de Paéz Urdaneta (1992) possui uma configuração interessante e necessária quando falamos de complexidade no âmbito organizacional. O modelo trabalha com três setores funcionais e específicas do processo de gestão da informação. Se inicia com o setor intitulado "Gestão de Recursos de Informação", que defende a realização de atividades que organizam os recursos de informação existentes no ambiente organizacional, bem como o desenvolvimento de estratégias que incentivam o aprimoramento da inteligência organizacional, o mapeamento da distribuição dos recursos de informação e o monitoramento do uso desses recursos.

O segundo setor atende pelo nome de "Gestão da Informação Estratégica" e busca a realização de atividades que alinham o planejamento corporativo com o produtivo, a obtenção de informações externas que agreguem nas atividades do ambiente interno organizacional e, de modo geral, a avaliação e levantamento de informações necessárias para apoio das atividades que são desenvolvidas dentro do ambiente laboral.

Por último, dentro desse modelo macro de gestão da informação, tem-se o setor "Gestão Holística da Informação", que agrega as atividades dos demais setores. As atividades da gestão holística da informação enfatizam a melhoria contínua das informações, a fim de promover qualidade e eficiência nos processos decisórios. Basicamente, o modelo de Paéz 
Urdaneta (1992) trabalha com três perspectivas: de gestão e organização dos recursos informacionais, de planejamento estratégico, ou seja, o que fazer com esses recursos informacionais, como utilizá-los e preservá-los a favor dos bons resultados que uma organização espera e a perspectiva holística, que desenvolve um alinhamento entre a gestão dos recursos com o planejamento estratégico que deve ser feito para que a gestão da informação seja valorizada e colocada em prática diariamente pelos sujeitos organizacionais.

\section{Pensamento complexo}

A Teoria da Complexidade parte primeiramente de uma tomada de consciência necessária ao seu entendimento e, principalmente, para sua existência na prática.Essa tomada de consciência acontece pelo princípio do saber, de que a sociedade é adepta a adquirir novos conhecimentos sobre o mundo físico, biológico, psicológico, sociológico, entre outros (MORIN, 2007).

Nesse contexto, da mesma maneira que a informação e o conhecimento perpassam o processamento cognitivo dos indivíduos, o erro, a cegueira e a ignorância se desenvolvem na mesma proporção. Para Neves e Neves (2006), a complexidade se encontra justamente nesse contexto, visto que ela envolve um conjunto de circunstâncias e possibilidades de relações, mesmo que essas relações sejam antagônicas entre si.Como continuidade e prática para desfazer o erro, a cegueira e a ignorância, surge o pensamento complexo como uma possível solução ou caminho para essa solução.

Entende-se complexidade como um "[...] tecido de acontecimentos, ações, interações, retroações, determinações, acasos, que constituem nosso mundo fenomênico" (MORIN, 2007 p.13). A complexidade está diretamente relacionada à interação de saberes, novas descobertas do saber e do fazer ciência, novas formas de agir, de adquirir conhecimento, de olhar a informação, novas formas de compreender a sociedade e seus fenômenos e, por fim, um novo modo de olhar o mundo e de vivê-lo.

À vista disso, Wallerstein (2002) declara que a ciência da complexidade busca o desenvolvimento e a evolução dos processos sociais e naturais do mundo. Nesse sentido, Bindé (2003) destaca que o mundo determinista, criador de uma ciência passiva e manipulável está por acabar, isso porque, para este autor, a sociedade contemporânea vivencia uma grande transformação, marcada pelo aumento da complexidade em seus processos que, por sua vez, afeta vários setores da sociedade. De acordo com este autor, essa complexidade traz em seu bojo o sentido de abraçar, entrelaçar, bem como pode até mesmo conduzir soluções auto-organizativas de desenvolvimento em diversos ambientes sociais e científicos.

Para Morin (2007), a complexidade surge da necessidade de estancar o determinismo 
absoluto do mundo, e para provocar inquietude, ordem e desordem nos acontecimentos. Nessa perspectiva, Larreta (2003) afirma que os novos processos de produção que estão relacionados às tecnologias e à informação, por si só são capazes de causar distâncias sociais entre os indivíduos de um mesmo contexto, ou seja, elitizar o acesso e a manipulação da informação. A complexidade evidenciada por Morin (2000), pode ser essencial para diminuir a distância dessa elitização, ao passo que vem para causar inquietude e estancar o determinismo do mundo.

Compreende-se que o pensamento complexo lida com a incerteza, contudo, encontrase preparado para reunir, contextualizar, globalizar e integralizar ideias, informação, conhecimento e áreas do conhecimento, bem como está apto em reconhecer o singular, o individual e o concreto (MORIN, 2000). O modo complexo de pensar

[...] não tem somente a sua utilidade para os problemas organizacionais, sociais e políticos. $O$ pensamento que afronta a incerteza pode esclarecer as estratégias do nosso mundo incerto. $O$ pensamento que une pode esclarecer uma ética da reunião e da solidariedade. O pensamento da complexidade tem igualmente os seus prolongamentos existenciais que postulam a compreensão entre os humanos (MORIN, 2000, p. 213).

O pensamento complexo é abrangente, se configura em inovação das práticas e paradigmas da sociedade e, concomitantemente, busca impedir que os membros dessa sociedade adormeçam na modernidade e no plano da separabilidade e simplicidade. No entanto, Morin (2000) explica que o pensamento complexo não tem o intuito de erradicar os princípios de ordem, separabilidade e de lógica, mas sim de integrá-los em uma concepção mais rica.

Gonzalez (2004) corrobora que a complexidade, também baseada na Teoria Geral de Sistemas e pelos processos auto-organizativos, possui potencialidade para aumentar a ação criativa dos indivíduos envolvidos em diversos contextos de transformação e desenvolvimento. Além disso, para este autor, sistemas complexos auto-organizados somente podem alcançar seus objetivos se trabalharem em totalidade interativa.

Nessa perspectiva, Paviani (2004) afirma que

[...] o homem precisa criar, participar da criação e que o desejo de criar é um desejo de imortalidade ou um desejo de compreensão radical de si mesmo. De fato, o homem não procura apenas entender as formas existentes, mas deseja produzir formas novas e redescobrir formas ocultas (PAVIANI, 2004, p. 282).

Percebe-se o quanto esse pensamento é relevante, ao observar que a Ciência nos moldes atuais, separa e reduz os conceitos e parâmetros científicos, a fim de torná-los mais simples (MORIN, 2007). Essa simplicidade caminha direto ao paradigma simplificador, que, de acordo com o autor, busca separar o que está ligado, unificar e reduzir o que é diverso, o que 
remete à inteligência cega, que

[...] destrói os conjuntos e as totalidades, isola todos os seus objetos do seu meio ambiente. Ela não pode conceber o elo inseparável entre o observador e a coisa observada. As realidades-chave são desintegradas. Elas passam por entre as fendas que separam as disciplinas. As disciplinas das ciências humanas não têm mais necessidade da noção de homem (MORIN, 2007, p. 12).

Desse modo, existem alguns princípios para reduzir e quebrar essa inteligência cega, e ao mesmo tempo, auxiliar no desenvolvimento do pensamento complexo. De acordo com Morin (2000), esses princípios são complementares e interdependentes:

(i) Princípio sistêmico ou organizacional: que corresponde ao fato de que é improvável conhecer o todo sem conhecer as partes e conhecer as partes sem conhecer o todo, mas que ao mesmo tempo, o todo é mais do que a soma das partes;

(ii) Princípio hologramático: explica, de certa maneira, porque a ideia reducionista deve ser apenas amenizada e não excluída. Este princípio evidência que cada parte desintegrada também pode ser vista como um todo que, de certa forma, expressa sua cultura;

(iii) Princípio do círculo retroativo: está relacionado à situação de causa e efeito, em que toda ação irá gerar fenômenos e efeitos, e ao mesmo tempo se insere no contexto de auto-regulação, onde há um feedback entre os processos de ação e efeito;

(iv) Princípio do círculo recursivo: apresenta que os indivíduos produzem a cultura da sociedade, e ao mesmo tempo é produto dela. Dessa forma, esse princípio enfatiza a representação de uma parte por um todo;

(v) Princípio da auto-eco-organização: denomina-se na necessidade e dependência da autonomia do ser humano, e possui forte característica no processo de regeneração e superação, ou seja, esse princípio encoraja o indivíduo a sempre recomeçar, independente dos problemas encontrados;

(vi) Princípio dialógico: afirma que elementos e forças antagônicas podem ser associados e complementares, por exemplo, na luta por um objetivo a ser alcançado. Por meio desse princípio, a ordem e a desordem não são elementos excludentes, muito pelo contrário, podem em conjunto e por ações interativas construir ou desconstruir determinado elemento ou situação;

(vii) Princípio da reintrodução do conhecimento em todo conhecimento: norteia-se pela necessidade de um ser cognoscente construir conhecimento por meio de outros conhecimentos. Esse princípio incentiva a crítica, a inovação e a valorização de todo conhecimento construído pelas mais diferentes pessoas. Para esse princípio todo conhecimento é bem-vindo e não há uma verdade absoluta.

Por fim, para Morin (2000), o princípio da Teoria da Complexidade serve como um instrumento que revela a defasagem conceitual da prática educacional da sociedade moderna, e como ferramenta e instrumento pós-modernos, indica medidas de superação do modo de pensar cartesiano, que se alicerça na separabilidade.

Em consonância, na concepção de Prigogine (2003), a complexidade pode ser vista como uma nova maneira de enxergar o mundo e as partes constituintes dele, isto é, equivale 
ao ato de desorganizar o determinismo clássico de um presente e um futuro já definidos, para organizar novamente, de uma maneira mais integrativa.

\section{Gestão da informação e complexidade}

A gestão da informação se alicerça nos fluxos formais de informação, que estão presentes em documentos, registros e sistemas de informação. Com o fato de que a Teoria da Complexidade possui como um dos seus pilares a Teoria Geral de Sistemas, pode-se afirmar que a gestão da informação possui relação com a Teoria da Complexidade.

Para Bertalanffy(1973), o conceito de sistema parece abstrato e vazio, mas na realidade, oferece múltiplas possibilidades de significados no contexto em que se está inserido.

Dessa maneira, os sistemas abarcam um conjunto de elementos que interagem entre si e com o todo, pois ao contrário não se configurariam em sistemas. Do ponto de vista humano, os indivíduos que executam etapas da gestão da informação em sistemas, também, são considerados sistemas que, por sua vez, contém subsistemas. A lógica está na interação entre os diferentes sistemas e, também, na configuração de uma gestão da informação que absorva essa característica.

A importância dessa interação se explica nas palavras de Bresciani Filho e D'Ottaviano (2000, p. 286):

As propriedades e o comportamento de cada elemento do conjunto têm
efeitos nas propriedades e no comportamento do todo, dependem das
propriedades e do comportamento de pelo menos um dos outros
elementos; ou seja, não existem elementos isolados no sistema; cada
possível subconjunto de elementos apresenta a mesma primeira
característica e, então, o conjunto não pode ser subdividido em
subconjuntos independentes (BRESCIANI FILHO; D'OTTAVIANO, 2000,
p.286).

As características mencionadas pelos autores supracitados (propriedade e comportamento de elementos) se constituem em uma das justificativas para que a gestão da informação e as pessoas que executam essa gestão adotem e internalizem as características do paradigma complexo, que surge para clarear e colocar em prática a interação.

Os modelos de gestão da informação apresentados demonstram ordem em sua aparência e aplicabilidade. Nesse contexto, a ideia de compreender a gestão da informação sob a concepção do pensamento complexo pode provocar desordem nessa suposta ordem, fato que de acordo com Morin (2008), não pode ser considerado como algo ruim, pois "[...] a desordem tem duas faces, sendo, por um lado, a destruição e, por outro lado, a liberdade, a criatividade. É certo que essa lógica de ordem, julgando-se racional, traz com ela a vontade de 
liquidar toda a desordem como nefasta e disfuncional" (MORIN, 2008, p.110).

Dessa maneira, democratizar, complexificar e desordenar aspectos da gestão da informação deve ser considerado um ato positivo e necessário no âmbito da sociedade contemporânea. Atlan (1992) destaca que a sociedade, em alguns aspectos, se alimenta de desordem.

A mudança é um processo necessário para qualquer tipo de ambiente organizacional, porque provoca inquietação, novas ideias e novas práticas que buscam adaptações a essas mudanças. Como a gestão da informação está inserida em ambientes organizacionais, torna-se também imprescindível que ocorram mudanças em suas estruturas.

Bresciani Filho e D'Ottaviano (2000) consideram a mudança como uma evolução criativa, caracterizada por estados de equilíbrio e desequilíbrio. Os sistemas de informação são desenvolvidos com base em mudanças da sociedade, portanto, a estrutura da gestão da informação pode caminhar com os mesmos propósitos.

Nessa perspectiva, o princípio sistêmico de Morin (2000) pode elucidar as práticas de gestão da informação que são realizadas pelos profissionais no contexto organizacional, no sentido que, por meio deste princípio, torna-se importante que o profissional conheça detalhadamente cada etapa correspondente à gestão da informação, mas principalmente que tenha consciência dos efeitos resultantes da soma de cada etapa realizada, ou seja, concomitantemente se relaciona ao princípio hologramático, que explica a relevância do reducionismo e da separabilidade serem apenas moderados e não suprimidos. Todas as etapas devem ser executadas, visto que são dependentes umas das outras e é por isso que, ao mesmo tempo, devem separadamente serem conhecidas de maneira detalhada.

Continuadamente, mesmo que as etapas e atividades da gestão da informação sejam padronizadas, é importante enfatizar que assim como no círculo recursivo, são os profissionais praticantes da gestão da informação os responsáveis por representar e caracterizar a gestão da informação que é utilizada no contexto organizacional. A representação cultural e comportamental atribuída às práticas da gestão da informação, resulta em efeitos bons ou ruins na organização, dependendo do modo como será praticado.

Além disso, a teoria da auto-organização, que é também base de um dos princípios do pensamento complexo, denominado como 'auto-eco-organização' e, também, uma das bases para a Teoria da Complexidade, compreende em um processo de interações e práticas sem comandos, ou seja, práticas e interações que ocorrem de maneira natural (DEBRUN, 1996).

Por fim, essa visão acerca da gestão da informação e do pensamento complexo pode ser considerada resultado da valorização do conhecimento, da cognição e da humanidade, seguindo o princípio de que não há verdades absolutas, e que tudo deve estar sempre em 
desenvolvimento e passíveis de contestações.

Infere-se que ao adotar um olhar complexo diante das atividades da gestão da informação, pode resultar em novos modelos, com novas etapas e atividades que, ainda, não foram notadas. Para Bresciani Filho e D'Ottaviano (2000) o processo de auto-organização decorre de trocas e relações com elementos e ambientes externos, assim como a informação e sua gestão.

\section{Considerações finais}

Buscou-se neste texto refletir sobre a gestão da informação, com base na concepção do pensamento complexo, bem como responder a seguinte problemática: é possível agregar valor às práticas tradicionais da gestão da informação,por meio dos princípios do pensamento complexo?

Percebeu-se, por meio das reflexões, que o único modelo dos apresentados neste artigo, que adotou em sua estrutura práticas que induzem a interação, é o de Valentim (2004), denominado de 'Atividades Base da Gestão da Informação'. As práticas são representadas pelas atividades: 'Desenvolver a cultura organizacional positiva em relação ao compartilhamento e socialização da informação' e 'Proporcionar a comunicação informacional de forma eficiente, utilizando tecnologias de informação e comunicação'.

A gestão da informação lida com sistemas de informação, é manuseada por seres humanos e está presente nos ambientes organizacionais. Todos esses elementos são sistemas, que, por sua vez, possuem como característica a interação entre as partes que formam o todo.

A partir da análise, o estudo propiciou a reflexão de que, inseridos nesse contexto, os modelos de gestão da informação devem adotar as características de interação.

À vista dessa reflexão, esse novo olhar para a estrutura da gestão da informação pode representar certo caos e desordem em um paradigma já padronizado, mas que, por outro lado, torna-se potencial em agregar valores democráticos que sigam o pensamento complexo.

Verificou-se que aspectos do pensamento complexo poderiam auxiliar na quebra de paradigma que habitam as práticas tradicionais dos modelos de gestão da informação. Nesse intuito, para uma melhor compreensão desse processo reflexivo, desenvolveu-se um mapa conceitual (Figura 1), de modo que sintetizasse os principais conceitos do artigo.

Figura 1: Mapa Conceitual: Gestão da Informação e Teoria da Complexidade. 


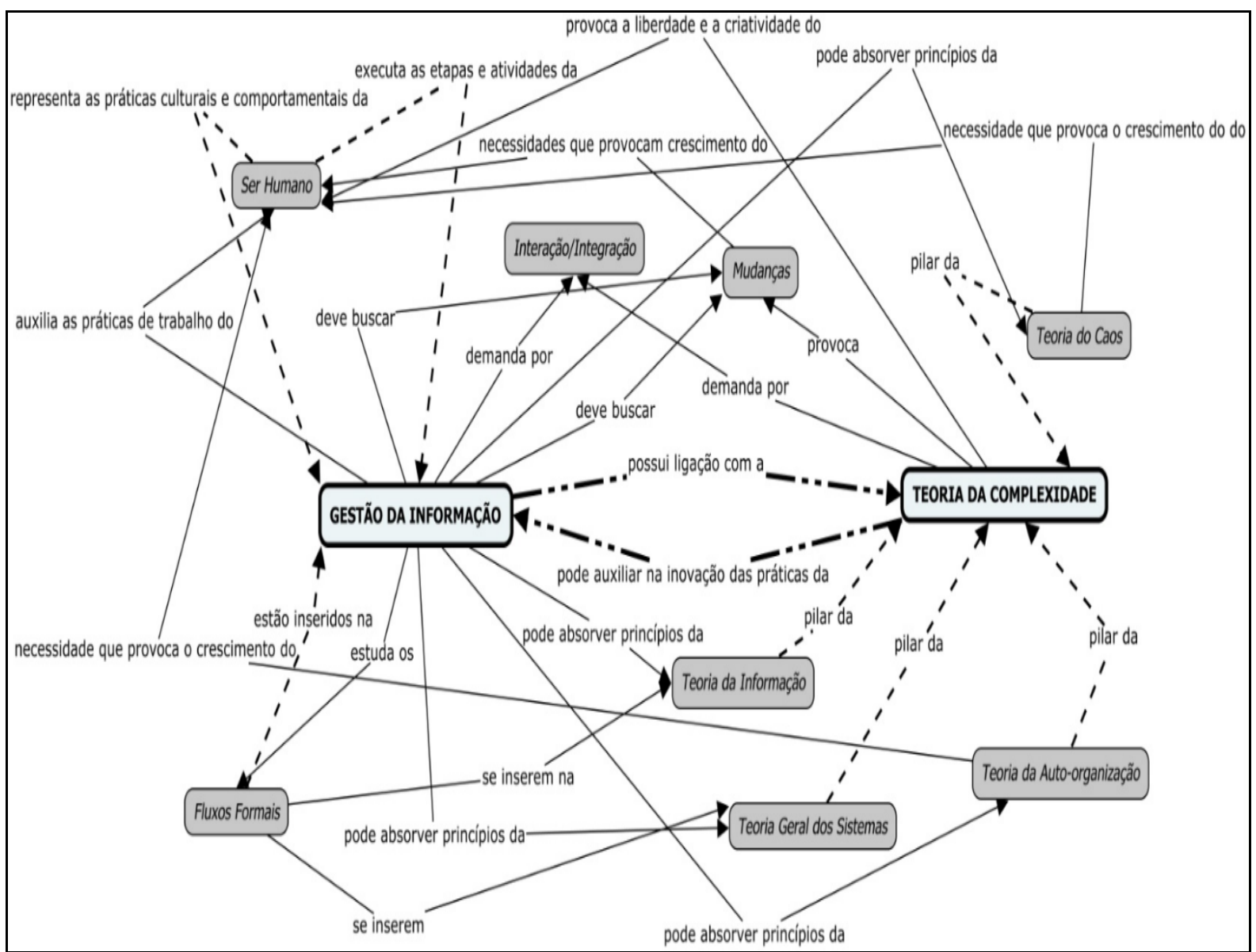

Fonte:Elaborada pelas autoras (2019).

Com base nas reflexões elaboradas por meio dos princípios do pensamento complexo, é notório que as etapas/atividades da gestão da informação devem estar inter-relacionadas, tendo como principal objetivo gerir a informação, a fim de agregar valor a ela, bem como utilizá-la nas tomadas de decisões. No entanto, não se deve descartar o desenvolvimento de cada etapa (parte), ou seja, o resultado do todo das interações é maior que a soma das partes, o que está em acordo com os princípios sistêmico e hologramático.

É relevante promover mudanças, reflexões e inquietações frequentes sob os modelos de gestão da informação e, ao mesmo tempo, compreender que essas mudanças ocorrem naturalmente, visto que suas práticas geram efeitos que necessitam estar sempre acompanhados das mudanças da sociedade. Os princípios que sustentam essa ideia são o princípio do círculo retroativo e o princípio de auto-eco-organização. Além disso, todo esse processo de mudanças e reflexões proporciona aos indivíduos envolvidos com a gestão da informação, a construção de novos conhecimentos. 


\section{Referências}

ATLAN, $\mathrm{H}$. Entre o cristal e a fumaça: ensaio sobre a organização do ser vivo. Rio de Janeiro: Zahar, 1992.

BARBOSA, R.R. Gestão da informação e gestão do conhecimento: origens, polêmicas e perspectivas. Informação \& Informação, Londrina, v.13, n.esp., p.1-25, 2008. Disponível em: $<$ http://www.uel.br/revistas/uel/index.php/informacao/article/view/1843/1556 >. Acesso em: 16fev. 2019.

BERTALANFFY, L.V. Teoria geral dos sistemas. Petrópolis: Vozes, 1973.

BINDÉ, J. Complexidade e crise da representação. In: MENDES, Candido (Org.). Representação e complexidade. Rio de Janeiro: Garamond, 2003. 248p.

BRESCIANI FILHO, E.; D'OTTAVIANO, I.M.L. Conceitos básicos de sistêmica. In: D'OTTAVIANO, I.M.L.; GONZALES, M.E.Q. (Org.). Auto-organização: estudos interdisciplinares. Campinas: UNICAMP, 2000. p.283-306.(CLE, 30).

CHOO, C.W. A organização do conhecimento: como as organizações usam a informação para criar significado, construir conhecimento e tomar decisões. São Paulo: Editora SENAC, 2003.

CHOO, C.W. Gestão de informação para a organização inteligente: a arte de explorar o meio ambiente. Lisboa: Caminho, 2003.

DAVENPORT, T.H. Reengenharia de processos. São Paulo: Campus, 1994.

DAVENPORT, T. H.; PRUSAK, L. Ecologia da informação: porque só a tecnologia não basta para o sucesso na era da informação. São Paulo: Futura, 2002.

DEBRUN, M. A dinâmica da auto-organização primária. In: DEBRUN, M.; GONZALES, M. E.; PESSOA JÚNIOR, O. (Org.). Auto-organização: estudos interdisciplinares. Campinas: UNICAMP, 1996. p.25-59. (CLE, 18).

GONZALEZ, M.E.Q. Complexidade e criatividade: uma abordagem sistêmica dos processos auto-organizados. In: CIRNE-LIMA, Carlos; HELFER, Inácio; ROHDEN, Luiz (Org..). Dialética, caos e complexidade. São Leopoldo: Editora Unisinos, 2004. 293p.

LARRETA, E.R. Transparências obscuras: pensar a complexidade no Século XXI. In: MENDES, Candido (Org.). Representação e complexidade. Rio de Janeiro: Garamond, 2003. 248p.

MADSEN, D. Disciplinary perspectives on information management. Procedia: Social and Behavioral Sciences, v.73, p.534-537, Feb. 2013. Disponível em: <https://doi.org/10.1016/j.sbspro.2013.02.087>. Acesso em: 16 fev. 2019.

MALIN, A.M.B. O campo profissional da gestão da informação. Informação \& Informação, Londrina, v.17, n.2, p.172-187, maio/ago. 2012. Disponível em: $<$ http://www.uel.br/revistas/uel/index.php/informacao/article/view/13697/pdf $>$. Acesso em: 16 fev. 2019.

MCGEE, J.; PRUSAK, L. Gerenciamento estratégico da informação. Rio de Janeiro: Campus, 1994. 
MORIN, E. Ciência e consciência da complexidade. In: MORIN, Edgar; LE MOIGNE, Jean-Louis (Org.). A inteligência da complexidade. São Paulo: Petrópolis, 2000. 265p.

MORIN, E. Introdução ao pensamento complexo. 3.ed. Porto Alegre: Sulina, 2007.

MORIN, E. Ciência com consciência. Rio de Janeiro: Bertrand Brasil, 2008.

NEVES, C.E.B.; NEVES, F.M. O que há de complexo no mundo complexo? Niklas Luhmann e a Teoria dos Sistemas Sociais. Sociologias, Porto Alegre, v.8, n.15, p.182-207, jan./jun. 2006. Disponível em: <http://www.scielo.br/pdf/soc/n15/a07v8n15.pdf>. Acesso em: 16 fev. 2019.

PAVIANI, J. Arte, complexidade e criatividade. In: CIRNE-LIMA, Carlos; HELFER, Inácio; ROHDEN, Luiz (Org.). Dialética, caos e complexidade. São Leopoldo: Editora Unisinos, 2004. 293p.

POMBO, O. Interdisciplinaridade e integração dos saberes. LIINC em Revista, Rio de Janeiro, v.1, n.1, p.3-15, mar. 2005.2 Disponível em: <http://revista.ibict.br/liinc/article/view/3082/2778>. Acesso em: 16 fev. 2019.

PONJUAN DANTE, G. Gestión de información en las organizaciones: dimensiones para el éxito organizacional. Rosario, Argentina: Nuevo Paradigma, 2004.

PRIGOGINE, I. O Fim da Certeza. In: MENDES, Candido (Org.). Representação e complexidade. Rio de Janeiro: Garamond, 2003. 248p.

SILVA, T.E. da.; TOMAÉL, M.I. A gestão da informação nas organizações. Informação \& Informação, Londrina, v.12, n.2, jul./dez. 2007. Disponível em: $<$ http://www.uel.br/revistas/uel/index.php/informacao/article/view/1806/1540>. Acesso em: 16 fev. 2019.

VALENTIM, M.L.P. Gestão da informação e gestão do conhecimento: especificidades e convergências. Londrina: Infohome, 2004. (Artigo em Web). Disponível em: <https://www.ofaj.com.br/colunas conteudo.php?cod=88>. Acesso em: 16 fev. 2019.

WALLERSTEIN, I. O fim do mundo como o concebemos: Ciência Social para o Século XXI. Rio de Janeiro: Revan, 2002.

WILSON, T. D. Information management. In: International Encyclopedia of Information and Library Science. 2.ed. London: Routledge, 2002.

WERSIG, G. Information science: the study of postmodern knowledge usage. Information Processing and Management, New York, v.29, n.2, p.229-239, Mar./Apr. 1993. Disponível em: <https://doi.org/10.1016/0306-4573(93)90006-Y>. Acesso em: 16 fev. 2019. 